\title{
Performance of vertical drains in liquefaction mitigation under structures
}

\author{
Samy García-Torres ${ }^{1} \cdot$ Gopal Santana Phani Madabhushi ${ }^{2}$
}

Received: 12 March 2019 / Accepted: 4 September 2019 / Published online: 12 September 2019

(c) The Author(s) 2019

\begin{abstract}
Several techniques have been developed in order to mitigate damage to buildings during and after liquefaction events. Benefits of using vertical drains have been verified by analysing their performance in the soil and evaluating their effectiveness in dissipation of excess pore pressures generated by the earthquake. However, the effect of drains in the soil below structures requires further investigation. In this paper, a dynamic centrifuge test series was carried out to evaluate the performance of a vertical drains arrangement below shallow foundations. High permeable rubble brick was used as coarse material inside the drains to provide positive results not only from a geotechnical point of view but also from an environmental and sustainable perspective. The behaviour of drains was analysed when they are located under shallow foundations of a building, in terms of the excess pore pressures generated during the earthquake and subsequent post-seismic dissipation, the foundation settlement and its dynamic response.
\end{abstract}

Keywords Liquefaction $\cdot$ Earthquakes $\cdot$ Centrifuge $\cdot$ Drains $\cdot$ Soil-structure interaction

\section{Introduction}

Constructions located in liquefaction prone areas are potentially exposed to harmful effects during a seismic event, particularly structures situated in regions lacking mitigation systems against liquefaction damage. The New Zealand earthquake of 2011 and the devastating liquefaction and lateral spreading at Christchurch bear testimony to this. Earthquake-induced liquefaction is a phenomena where loose saturated soil losses notably shear strength as a consequence of excess pore pressure build up generated by cyclic loading (Florin and Ivanov 1961). Its effects involve rotation and/or settlement of buildings as the bearing capacity is adversely affected due to the fluidisation of soil behaviour (Haigh et al. 2000). Over the last decades, several liquefaction cases have been identified, revealing significant damage to buildings and justifying the importance of continued research on countermeasure techniques to reduce infrastructure damage. Prior to the Indonesian earthquake

Samy García-Torres

sssg2@cam.ac.uk

1 Department of Engineering, Schofield Centre, University of Cambridge, Cambridge CB3 0EL, UK

2 Department of Engineering, University of Cambridge, Cambridge CB2 1PZ, UK 
of 2018, the Kocaeli earthquake in 1999 (Yoshida et al. 2001) and the Christchurch case in 2010-2011 (Cubrinovski et al. 2011) are two examples that highlighted the importance of assessing liquefaction potential under buildings as tilt and settlement of several constructions were observed. It is often difficult to impede liquefaction occurrence; however, research on methods to minimise negative impact focusing on the adequate building performance can be developed.

The effectiveness of a countermeasure technique is related to the building damage mitigation considering as principal aim the structures usability post liquefaction event. The use of vertical drains has proven to be effective in reducing damage to buildings by controlling the generation of pore pressure and allowing a rapid dissipation of excess pore pressures during co-seismic and post-seismic periods, thereby reducing the building's risk to suffer settlement and/or tilt (Brennan and Madabhushi 2002). Furthermore, engineering solutions such as drains are required to be associated with a sustainable approach, and be economical, as they may only be called into action once or twice during the life time of the building. In this regard, vertical drains become an attractive method to accomplish this aim as it allows the use of construction debris and other waste material to be reused as high permeability coarse material inside the drains.

Soil-foundation interaction considering the possible reinforcement effects provided by countermeasure techniques such as vertical drains, demand extensive physical modelling. While the geotechnical practice relies on the use of theoretical procedures developed for a free field context, there is a need for experimental investigation of the performance of the vertical drains in presence of building foundations. This paper is focused on the evaluation of sustainable rubble brick vertical drains behaviour below a shallow foundation, considering the generation and dissipation of excess pore pressure generated due to an earthquake loading and the subsequent foundation response.

\section{Previous studies}

Buildings settlement and rotation are two of the most dangerous liquefaction effects; therefore, a large amount of research focused on the reduction of the detrimental effects have been developed by improving the soil below structures. Niigata earthquake in 1964 has been the started point for several studies centred on mitigation techniques for protection of buildings against liquefaction phenomenon (Yasuda 2007). Although significant destruction was observed during Niigata seismic event, the effectiveness of using countermeasure techniques was confirmed due to the minor damage presented in certain locations previously improved by compaction techniques (Watanabe 1966).

Densification of soil, dewatering and drainage are the most utilised liquefaction mitigation techniques used by the industry (Brennan 2004) and relevant research has been elaborated on their performance. Liu and Dobry (1997) worked on densification of sand to evaluate mechanisms of settlement generated by liquefaction in the soil. Coelho et al. (2004) looked at densification underneath bridge foundations to prevent the detrimental effects of liquefaction. Adalier et al. (1998) performed centrifuge tests to analyse countermeasure techniques for embankments over foundations, working with gravel berms and soil densification. The evaluation of the foundation dynamic response concluded that positive results with respect to settlement reduction are possible. Moreover, Mitrani and Madabhushi (2012) performed centrifuge tests to study containment walls proving their effectiveness in settlement minimisation and the relevance of the wall permeability as an 
important parameter. Dashti et al. (2010a, b) performed centrifuge tests to analyse the better understanding of settlement mechanisms during earthquakes by using structural walls and water impermeable barrier as mitigation techniques. Also, Tanaka et al. (1996) worked with steel sheet piles to evaluate the soil improvement focusing on their drainage potential.

\subsection{Vertical drains as mitigation technique}

Drainage technique is considered an optimum method against liquefaction as their main objective is to prevent large levels of excess pore pressure generation due to their faster dissipation. Initial work on this subject was elaborated by Seed and Booker (1977) where gravel drains efficiency as a method to reduce damage and the stabilisation of sand deposits was calculated theoretically. Shaking table tests were performed by Iai et al. (1988) and Sasaki and Taniguchi (1982) to analyse gravel drain behaviour in liquefiable sand, showing the relevant advantages on the dissipation of excess pore pressure.

In addition, centrifuge modelling is a methodology that have been used to analyse vertical drains effectiveness. Brennan and Madabhushi (2002) studied the efficiency of this technique by analysing dissipation rates and reconsolidation of liquefied soil by estimating the densification front arrival times in presence of vertical drains. Moreover, nomenclature of perimeter, sub-perimeter and internal drains was originally proposed by Brennan (2004). According to him, drains are classified depending on their location in the arrangement. "Perimeter drains" are placed in the outer ring of the arrangement, receiving constant fluid from far-field. Drains located between the internal and the perimeter rings are named "sub-perimeter drains". Their work is considered more effective compare to the perimeter drains as they are in charge of dissipating restricted amount of fluid. Finally, the internal or nucleus drains are responsible of limited flow enclosed by a specific area of influence, for this reason they present higher efficacy. The effectiveness of vertical drains as a countermeasure technique relies on a proper scheme of drain rings as they have specific roles in the dissipation of excess pore pressure. Research work elaborated by Paramasivam et al. (2018) was centred on the use centrifuge modelling to analyse the influence of prefabricated vertical drains on soil and structure behaviour. Although foundations accelerations showed amplification values, positive results related to settlement, duration and dissipation of excess pore pressures were obtained. Badanagki et al. (2018) studied the influence of granular columns in sloped sites during shaking by applying dynamic centrifuge methodology. Howell et al. (2012) verified the improvements in settlement reduction and dissipation of excess pore pressures by working on a comparison between a soil region treated with prefabricated drains and a region without them. Also, Olarte et al. (2017) evaluated structures response over saturated soil using three different mitigation techniques, such as densification of soil, prefabricated vertical drains and ground reinforcement using structural walls. The effects of each technique on the soil and the foundation behaviour during and after the shaking were analysed. Although the performance of vertical drains in the presence of high confining stresses imposed by the foundations of buildings have been previously investigated, this paper aims to study the influence of the foundation and the pore pressure redistribution below the structure in the presence of a group of vertical drains.

\subsection{Alternative sustainable material}

The reuse of construction materials from buildings demolition or post-earthquake debris from collapsed buildings is a major concern as they are closely related to the environment 
welfare. Demolition of constructions is a regular activity in many countries due to the important increase in land urbanisation. According to Ledesma et al. (2015) in the European Union extensive amounts of masonry waste from construction demolition were registered in the last few years and a large percentage of them do not go through a proper waste treatment. Moreover, the number of landfills are not able to cope the total waste material (Nataatmadja and Tan 2001) evidencing not only the large amounts of construction debris but the limited availability of landfills to allow suitable disposal areas. Hence, a proper end-of-life scenario that involves the reuse of these materials in the geotechnical field, becomes an attractive solution.

Several studies have been elaborated on the reuse of construction waste material frequently with the common purpose of being used in the construction sector, this means as fine or coarse aggregate (Rao et al. 2007). Ulsen et al. (2013) analysed the properties of recycled sand obtained from construction materials and Miranda et al. (2012) evaluated clean recycled sand characteristics after accumulating demolition and construction debris in Brazil. Furthermore, recycled concrete has been the most popular material used as coarse aggregate. Etxeberria et al. (2007) and Ravindrarajah et al. (1987) elaborated new concrete using recycled crushed concrete as aggregate and analysed the new material properties.

In the geotechnical field, the behaviour of reused construction materials inside vertical drains have been evaluated during the last decades. Gravel drains containing crushed concrete inside were analysed by Orense et al. (2003) using shaking table tests, suggesting positive results. Moreover, Ghajj et al. (2008) worked with coir and beach sand inside drains in order to evaluate the drain material permeability and its advantages in the soil improvement. This paper is focused on the use of rubble brick as vertical drains filling material.

\section{Behaviour of foundations in improved and unimproved soil using centrifuge modelling}

\subsection{Testing details}

The model presents a foundation of $150 \mathrm{kPa}$ over loose sand soil enclosing a rectangular arrangement of vertical drains in one region of the container. Similar foundation is located over soil with no drains in the remaining half (Fig. 1). The foundations were represented by rectangular blocks of brass material, with cross-sectional area of $60 \mathrm{~mm} \times 60 \mathrm{~mm}$ and height of $35 \mathrm{~mm}$ in model scale to represent prototype foundations of $3 \mathrm{~m} \times 3 \mathrm{~m} \times 1.75 \mathrm{~m}$. These blocks were separated by about $4.5 \mathrm{~B}$ (where $\mathrm{B}$ is the width of the foundation block) to avoid any foundation interaction. Studies on shallow foundations by Heron et al. (2014) and Adamidis and Madabhushi (2015) use similar foundation spacing to avoid undesirable interaction. A dynamic centrifuge test series was performed using 1:50 scale to evaluate the behaviour of vertical drains in the soil below shallow foundations. The Turner Beam Centrifuge of University of Cambridge was used to carry out the test and the earthquakes were generated using the Servo-Hydraulic actuator (Madabhushi 2014). The laminar box (Brennan et al. 2006) was utilised as soil container and pore pressures transducers together with accelerometers at two different depths were placed in the soil (Fig. 1). After the sand pouring, the model saturation was developed employing the Schofield Cam Sat System (Stringer and Madabhushi 2009) and solution of hydro propyl methylcellulose (HPMC) 


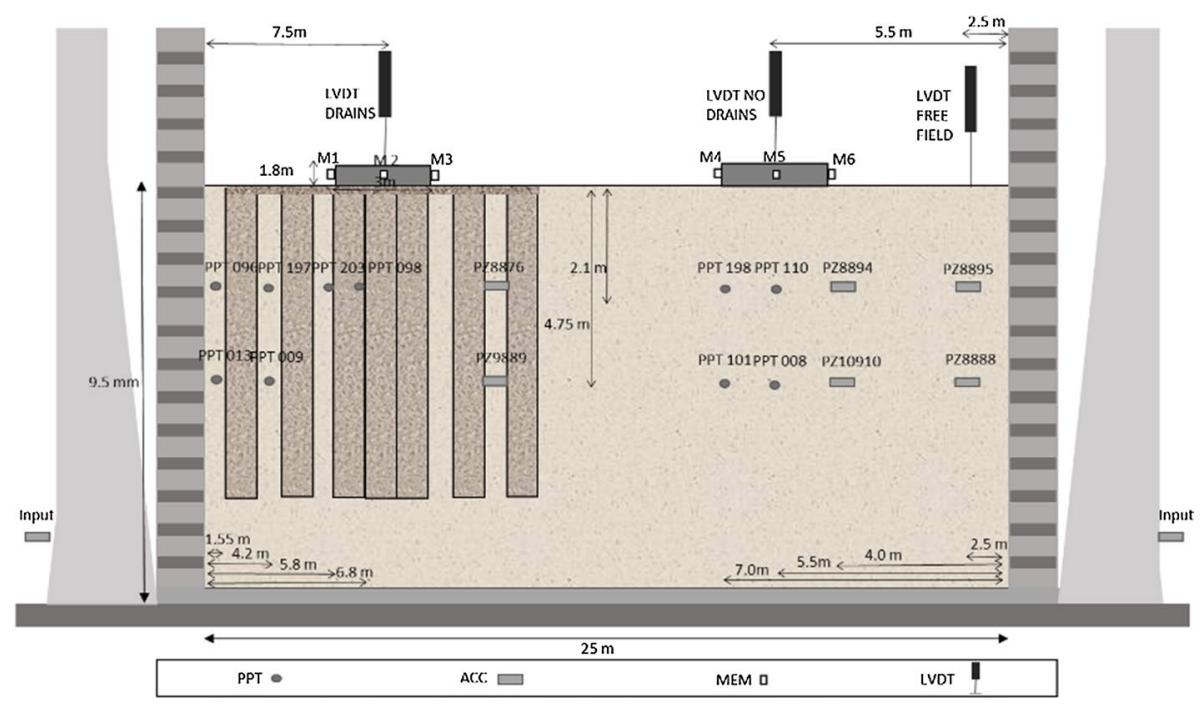

Fig. 1 Centrifuge test layout in prototype scale

to increase viscosity in the fluid. In dynamic centrifuge modelling, higher viscosity fluids are used to saturate the model so that the scaling laws for the rate of excess pore pressure generation match with the scaling laws for the excess pore pressure dissipation processes (i.e. consolidation rate). More details of this technique are given by Schofield (1980) and Madabhushi (2014).

\subsection{Model construction}

Hostun sand was poured in the laminar box using the automatic sand pourer machine at the Schofield Centre (Madabhushi et al. 2006). After pouring a certain height of sand, paper tubes with a radio of $0.5 \mathrm{~m}$ and a height of $7.1 \mathrm{~m}$ in prototype scale were placed at the sand surface on one side of the box (Fig. 1). The sub-perimeter and perimeter drains outside the foundation together with the central drain form equilateral triangles with a separation of $3 \mathrm{~m}$. and a ratio $\mathrm{a} / \mathrm{b}$ of 0.3 ( $\mathrm{a}=$ drain radius, $\mathrm{b}=$ half of the spacing between drains). The internal drains situated in a cross shape below the foundation form a nucleus cell with four edge drains and one central drain (Fig. 2). The complete drain arrangement was sealed at the top of the tube before continuing with the sand pouring in order to avoid any particle of fine sand inside them. Later, the paper tubes were filled with the rubble brick and then removed leaving the coarse material inside the soil. This drains arrangement was designed based on previous studies performed by Brennan (2004) and on the relevance of drain rings in the effectiveness of the technique.

The coarse material permeability is a critical factor in this work as vertical drains must contain higher permeable material inside them compared to the free field soil. Furthermore, more permeable soil is related to a larger particle grain size and a higher amount of voids in the soil, increasing the probability of clogging in drains. Thus, the rubble brick grain size range was obtained by following the anti-clogging criterion suggested by Orense et al. (2003) for crushed stone inside drains. Details of both material properties together with their permeability values are shown in Table 1 . It must be pointed out that the brick 


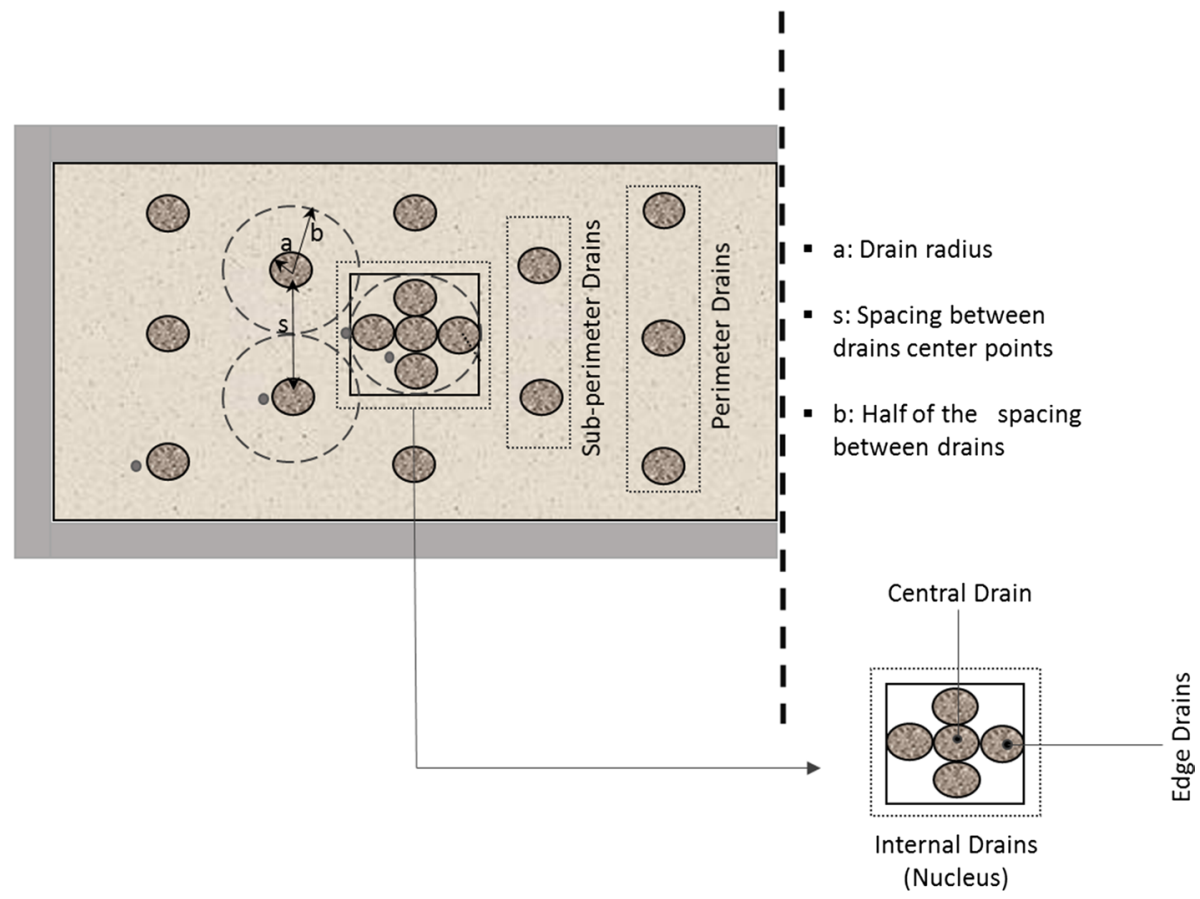

Fig. 2 Vertical drains positions in the horizontal plane

Table 1 Soil properties

\begin{tabular}{llclll}
\hline & $\begin{array}{l}\text { Density } \rho_{\mathrm{d}} \\
\left(\mathrm{kg} / \mathrm{m}^{3}\right)\end{array}$ & Permeability k $(\mathrm{m} / \mathrm{s})$ & Void ratio e & $\begin{array}{l}\text { Specific } \\
\text { gravity Gs }\end{array}$ & ${\text { Grain size } \mathrm{D}_{50}(\mathrm{~mm})}$ \\
\hline Hostun sand & 1417 & $1 \times 10^{-3 \mathrm{a}}$ & $0.87^{\mathrm{a}}$ & $2.65^{\mathrm{a}}$ & $0.48^{\mathrm{a}}$ \\
Brick rubble & 1560 & $1.5 \times 10^{-3}$ & 1.49 & $2.00^{\mathrm{b}}$ & $1.7-3.3$ \\
\hline
\end{tabular}

${ }^{\mathrm{a}}$ Haigh et al. (2012)

${ }^{\mathrm{b}}$ Vinodhini and Dhanalakshmi (2016)

rubble used in this study to model construction debris is a rudimentary attempt, with much emphasis placed on the permeability of the drain material. Other construction debris, for example using masonry of concrete debris can be carried out in a similar manner, if the results of this study show promise.

\subsection{Model earthquakes}

The $50 \mathrm{~g}$ dynamic centrifuge tests were performed and three different earthquakes were applied to the models. The first two earthquakes presented a sinusoidal behaviour with peaks accelerations of $0.08 \mathrm{~g}$ and $0.18 \mathrm{~g}$ in prototype scale and a total time of $10 \mathrm{~s}$. The second input motion was performed as negligible excess pore pressures build up during the first earthquake. The third is an Imperial Valley earthquake with high frequency content, peak value of $0.08 \mathrm{~g}$ and a duration of $60 \mathrm{~s}$ (Table 2). Figure 3 shows input motions for the 
Table 2 Input motions

\begin{tabular}{llllll}
\hline Earthquake & \multicolumn{2}{l}{ Duration $(\mathrm{s})$} & & \multicolumn{2}{l}{ Peak acceleration $(\mathrm{g})$} \\
\cline { 2 - 3 } \cline { 5 - 6 } & Model & Prototype & & Model & Prototype \\
\hline EQ1 & 0.2 & 10 & & 3.0 & 0.06 \\
EQ2 & 0.2 & 10 & & 9.0 & 0.18 \\
Imperial Valley & 1.2 & 60 & & 4.0 & 0.08 \\
\hline
\end{tabular}
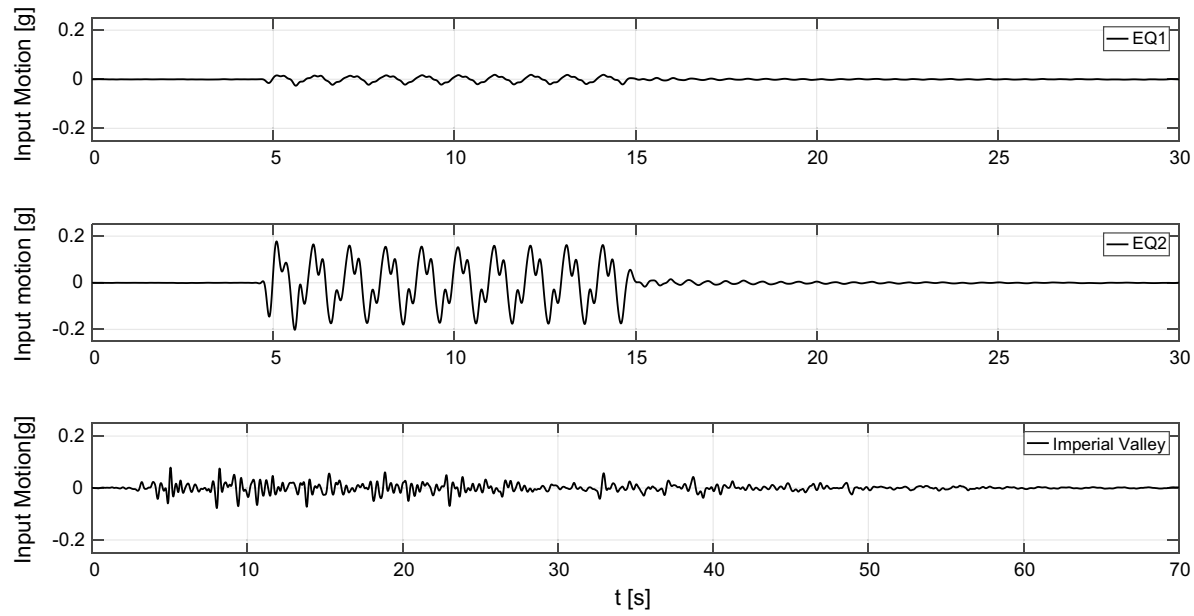

Fig. 3 Centrifuge test input motions

three earthquakes with a variation in the time scale for the Imperial Valley earthquake as it has a different duration.

\section{Pore pressures behaviour}

\subsection{Pore pressure time-histories for mitigated and unmitigated soil}

The high levels of excess pore pressure generated by the shaking affects the soil stiffness during the liquefaction phenomenon generating settlement of shallow foundations. Figure 4 compares time histories of excess pore pressures for the edge and central axis below foundations in both regions of the soil for the second earthquake, as it represents the strongest motion. Figures include the generation and dissipation phases together with a vertical dash line that represents the initiation of excess pore pressure dissipation.

For both soil regions, the greatest impact in the generation of pore pressures was produced during the start of the shaking at $t=5 \mathrm{~s}$. In the unmitigated region (Fig. $4 \mathrm{~b}$ ), instruments placed at the edge of the foundation (PPT198) show lower excess pore pressures values compared to the central axis (PPT110) during all the shaking phase as there was an absence of initial shear stress in this central area (Bertalot and Brennan 2015). In the soil with drains (Fig. 4a), excess pore pressure reached a value of $9 \mathrm{kPa}$ (PPT 203) at the foundation edge, less than the value of $11 \mathrm{kPa}$ registered at the central axis (PPT 098). The 


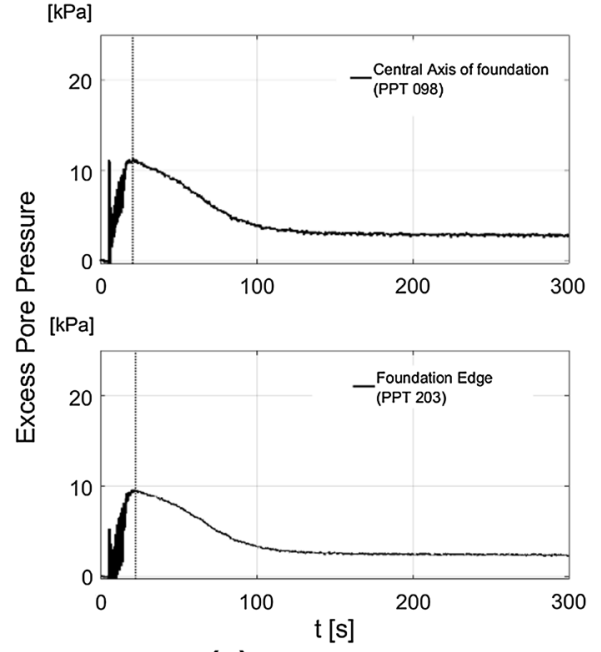

(a) Improved Region

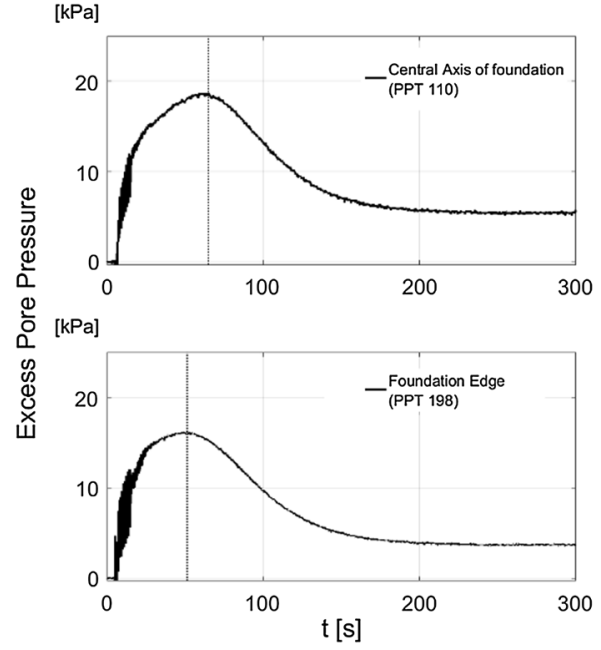

(b) Unimproved Region

Fig. 4 Excess pore pressure time histories for improved and unimproved soil at the central axis and edge below the foundations for a depth of $2.1 \mathrm{~m}$

inbound flow from the soil outside the foundation towards the area enclosed by the drains nucleus and the capacity of the soil to reach high pore pressures values in presence of large confinement allow greater excess pore pressures at the central axis.

Smaller excess pore pressure values were generated in the presence of drains for the central and edge axis compared to the unmitigated soil, suggesting the effectiveness of the vertical drains in regulating the levels of excess pore pressures during the generation stage, besides their effectiveness during dissipation (Badanagki et al. 2018).

The dissipation stage started at $\mathrm{t}=22 \mathrm{~s}$ at the edge of the foundation over drains and at $\mathrm{t}=52 \mathrm{~s}$ in the same location for the unmitigated soil (Fig. 4a, b). The soil at the central axis below the foundation started to dissipate at $t=24 \mathrm{~s}$ and $\mathrm{t}=55 \mathrm{~s}$ in the mitigated and unmitigated soil respectively. Spatial variation of the excess pore pressure dissipation and detailed explanation of the drain behaviour is presented in Sect. 4.2 for both soil regions.

\subsection{Spatial variation of excess pore pressures dissipation}

The following section is focused on the behaviour of excess pore pressures dissipation in the presence of vertical drains considering the concept of arrival of flow fronts, as the latter permits the evaluation of the effectiveness of the drain arrangement. Flow front is the term given to a boundary that represents the division between the soil influenced by the drain and the region that is not. The pore pressure dissipation initiation time at a certain point in the soil is called flow front arrival time (Brennan 2004).

Figure 5 shows contours of excess pore pressure in prototype scale during the dissipation stage considering the soil with drains (Fig. 5a) and with no drains (Fig. 5b). For the treated region, contours corresponding to the area enclosed by the drains perimeter ring were plotted. On the other hand, only the area below the foundation was illustrated for the untreated region. These contours were evaluated using Matlab cubic interpolation 


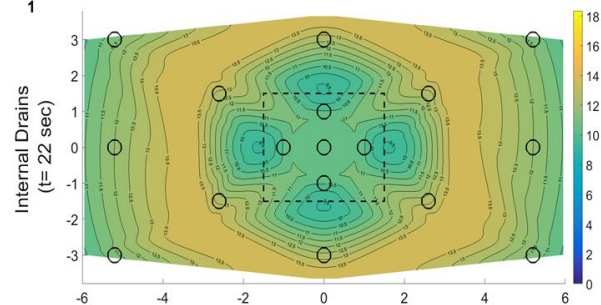

(m)
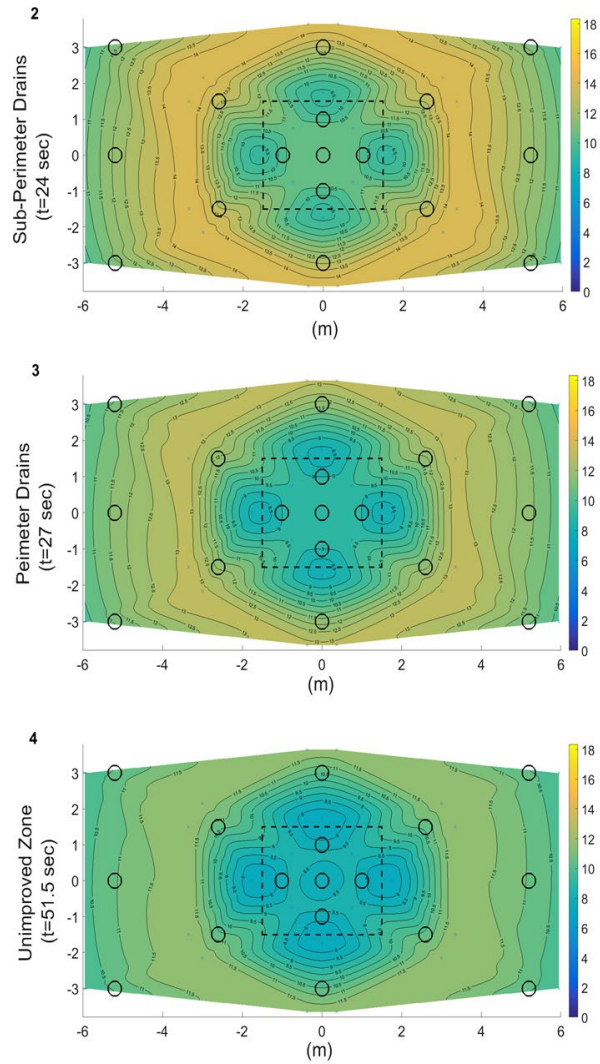

(a) Improved Region

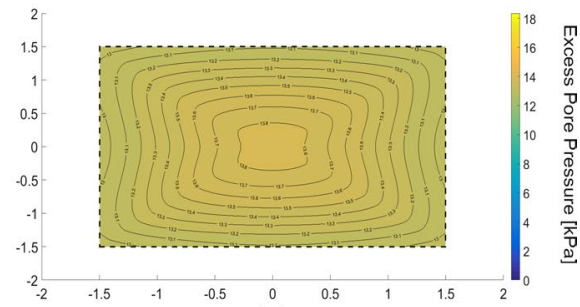

(m)

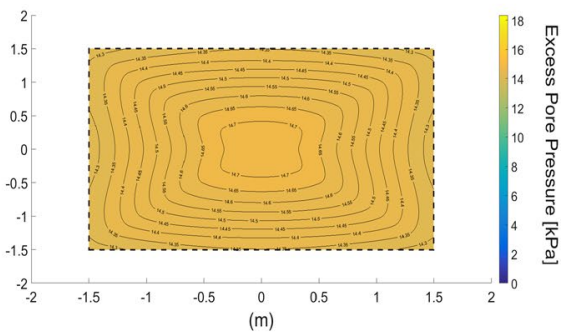

(m)

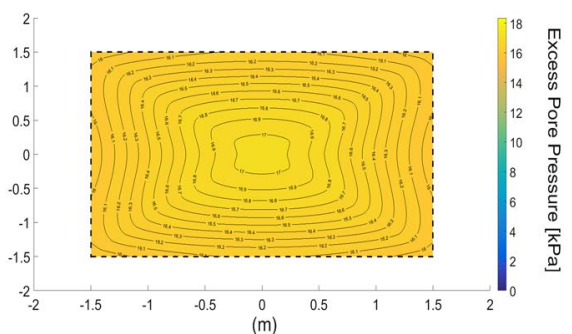

(m)

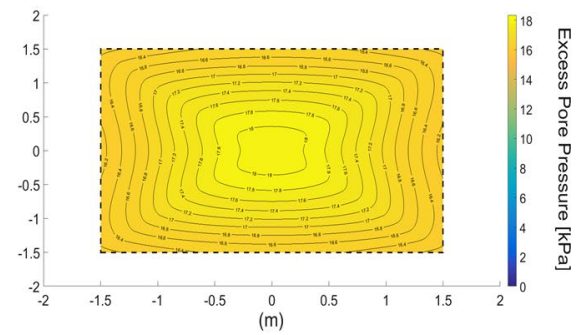

(b) Unimproved Region

Fig. 5 Contours of excess pore pressure in the horizontal plane at dissipation initiation times for a improved and $\mathbf{b}$ unimproved regions at a depth of $2.1 \mathrm{~m}$

function considering real and symmetry points that were obtained from the selected drains arrangement symmetrical shape. Foundations and drains are represented by dotted line squares and circles that are not necessarily at real scale. The use of these plots gives a clear appreciation of the drains behaviour below the foundations on the horizontal plane. Considering the pore pressure transducers locations in both regions and the order of dissipation initiation times, four flow front arrival times were illustrated and analysed for a depth of $2.1 \mathrm{~m}$ below the soil surface. 
The first flow front arrived at $\mathrm{t}=22 \mathrm{~s}$ in the improved soil (Fig. 5-1a) close to the drains nucleus which is acting as a unit cell encasing boundaries that limits the area where the flow is completely controlled by the drain (Brennan 2004). The dissipation stage started at this location as a consequence of the five vertical drains rapid action below the foundation that direct the majority of the flow towards the drains arrangement central area with more evident effective work performed by the edge drains. Additionally, faster dissipation behaviour below the foundation was expected as high bearing pressure makes difficult to hold high levels of excess pore pressure in the soil (Dashti et al. 2010a).The edge and central drains inside the nucleus show values of $9 \mathrm{kPa}$ and $11 \mathrm{kPa}$ respectively, indicating a faster dissipation below the foundation in the mitigated soil compared to the soil with no vertical drains (Fig. 5-1b).

After the internal drains flow front arrival, dissipation occurred close to the sub perimeter drains at $\mathrm{t}=24 \mathrm{~s}$ and near the perimeter drains at $\mathrm{t}=27 \mathrm{~s}$ (Fig. 5-2a, 5-3a). The proximity of the sub perimeter drains to the foundation and the drain nucleus allow a faster dissipation of the excess pore pressures generated over this zone. On the contrary, the continuous fluid flowing towards the perimeter drains from the far-field causes them to maintain high levels of pore pressures (Brennan 2004) and become the last drains ring to act. In addition, during this time excess pore pressures continued declining close to the drain nucleus following the same behaviour of faster dissipation at the edge during all the dissipation stage. In the unimproved soil, pore pressures below the foundation (Fig. 5-2b, 5-3b) were not dissipating, they show a slightly increase of pore pressure for some seconds after the shaking stage especially in the central axis due to the fluid coming up from the base of the stratum after the earthquake. The nucleus drains below the foundation (see Fig. 2) play an important role in the rapid dissipation of excess pore pressures. This action is in addition to any stiffness provided by these drains. Without the nucleus drains, the excess pore pressures will be held for longer, prolonging the time during which detrimental settlements can occur. In the presence of the nucleus drains, this will be avoided.

The last Fig. 5-4 corresponds to the dissipation initiation time of the unmitigated zone. This flow front arrived at the foundation edge reaching a value of $16 \mathrm{kPa}$ (Fig. 5$4 \mathrm{~b}$ ), while at this time, the mitigated region was approaching to a complete dissipation stage below the foundation (Fig. 5-4a) showing values of $8 \mathrm{kPa}$ at the edge and $9 \mathrm{kPa}$ at the central axis. Moreover, to this point all the drain rings were participating on the dissipation of excess pore pressures.

The performance of a vertical drain arrangement containing 17 drains on a hexagonal pattern with a single central drain in the internal ring and no shallow foundations on the surface has been previously evaluated using centrifuge modelling by Brennan (2004). Drains with a ratio of $\mathrm{a} / \mathrm{b}=0.4$ and height of $18.4 \mathrm{~m}$ in prototype scale were modelled using permeable coarse sand. Flow front arrival times during the dissipation stage were expected to differ in this work as the addition of edge drains surrounding the central drain in the nucleus area and the influence of the foundation at shallow levels allowed a faster dissipation of excess pore pressures. The structure response in presence of vertical drains in the soil is one of the main highlights that make this study different to previous work related to vertical drains performance. Although low magnitudes of volumetric strains in the co-seismic and post-shaking stages were expected by placing additional drains under the foundation, large total settlement values were obtained as a consequence of deviatoric strains. 

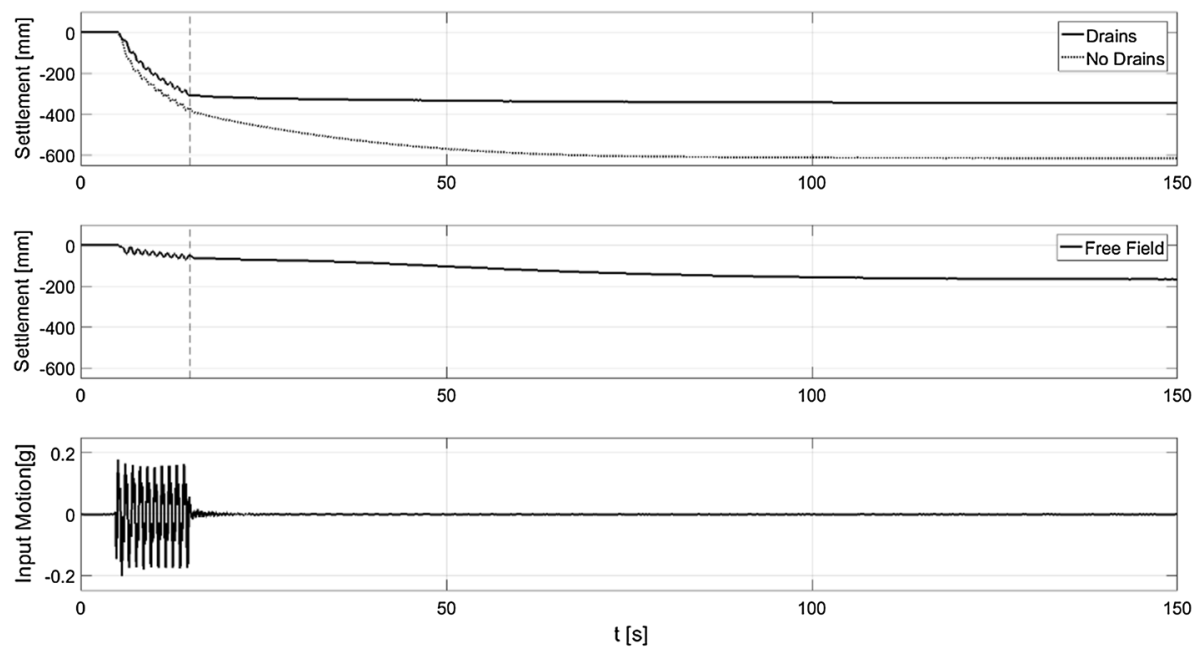

Fig. 6 Settlement time histories of foundations over the soil with drains, no drains and in free-field (EQ2)
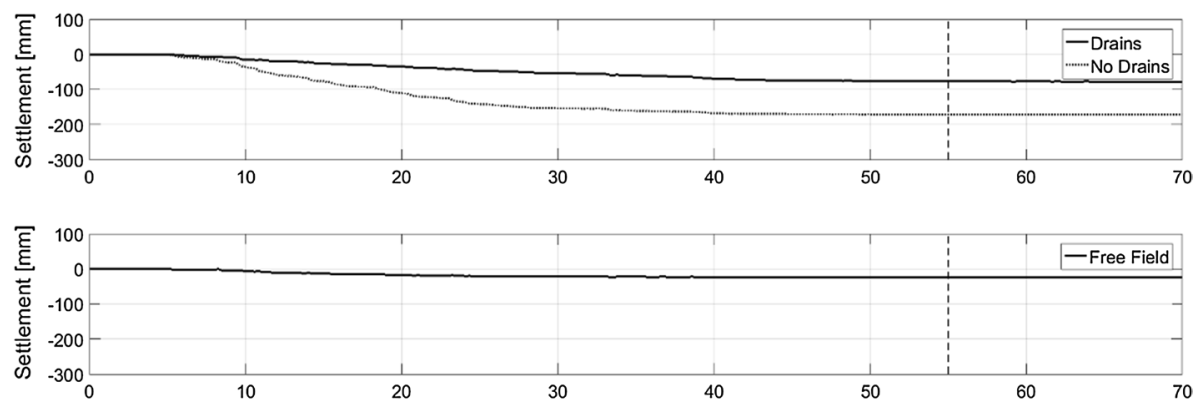

$\mathrm{t}[\mathrm{s}]$

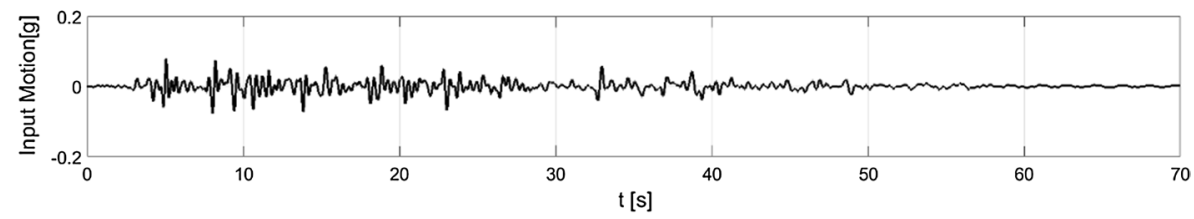

Fig. 7 Settlement time histories of foundations over the soil with drains, no drains and in free-field (Imperial Valley)

\section{Settlement of structures}

Settlement time histories obtained from LVDTS located over the foundations on both regions of the soil i.e. over the drains and in the free field are shown in Figs. 6 and 7 for EQ2 and Imperial Valley earthquakes. Vertical lines in the plots refer to the earthquake ending time.

During the first instants of the second earthquake, free field soil together with both foundations started to settle (Fig. 6). The free field settlement reached a value of $100 \mathrm{~mm}$ during the 
shaking and a total settlement of $190 \mathrm{~mm}$ including the dissipation stage. Volumetric strains as a consequence of drainage and re-consolidation of the soil were presented in the free field (Dashti et al. 2010b), including consolidation volumetric strains after the shaking.

Foundation settlement in the improved soil is related to the shaking effects as nearly $75 \%$ of the total amount was reached during this stage. In the presence of drains, the foundation settlement of $300 \mathrm{~mm}$ was obtained as a result of volumetric deformation in the soil generated by consolidation settlement and drainage, together with deviatoric strains generated below the structure. Dissipation was faster in the presence of vertical drains particularly under the foundation, reducing the soil settlement time and the subsequence volumetric strains during the post shaking stage. On the other hand, in the untreated soil settlement reached a total value of $610 \mathrm{~mm}, 400 \mathrm{~mm}$ during the shaking and $205 \mathrm{~mm}$ during the post-shaking stage.

Total settlement obtained in the dissipation stage for the foundation in the unimproved zone are double those on the improved soil as a consequence of the larger period for which high pore pressures were maintained compared to the soil with drains. In addition, this reduction in settlement could not be partially attributed to the shear reinforcement given by the drains as they lost stability due to loss of confinement as the surrounding soil completely liquefied. Although the shear strength of the drain material may be high, once the surrounding soil has liquefied the drains lost lateral support and therefore bulged out. This meant that the foundation could settle and any vertical strain in the drain material simply translated into lateral straining of the drains, observed as bulging in post-test investigations. This was discussed by García-Torres and Madabhushi (2018). A reduction of $40 \%$ in the case of soil with drains was obtained confirming the effectiveness of vertical drains in reducing settlement of foundations. It must be pointed out that the effect of locked-in horizontal stresses that may be generated during the drain installation were not modelled in these centrifuge tests. However, any increased horizontal stresses that are locked-in in the actual field, will further improve the performance of the drains.

Settlement time histories observed during the Imperial Valley earthquake motion are shown in Fig. 7. Low settlement values were obtained for the three locations as this earthquake represents a significantly smaller magnitude event compared to the previous input motions. However, reduction of foundations settlement due to the drain arrangement in the soil can still be verified. The foundations settlement were principally generated by volumetric strains during drainage and deviatoric strains generated in the co-seismic period by the bearing capacity loss.

The total foundation settlement in the improved soil reached a value of $110 \mathrm{~mm}$, half of the complete settlement obtained from the unimproved soil. In both cases, the greatest soil deformation occurred during the co-seismic period. The Imperial Valley earthquake generated lower pore pressures and the high bearing pressure below the foundation increased confinement in the soil for both cases, making it difficult for the generation of high levels of pore pressure (Paramasivam et al. 2017). Settlement in the free field reached a value of $30 \mathrm{~mm}$, with almost no post-shaking settlement. The free field soil settled less than both foundations principally due to the additional shear strains generated by the foundations (Olarte et al. 2017; Paramasivam et al. 2018) even in small earthquakes. 

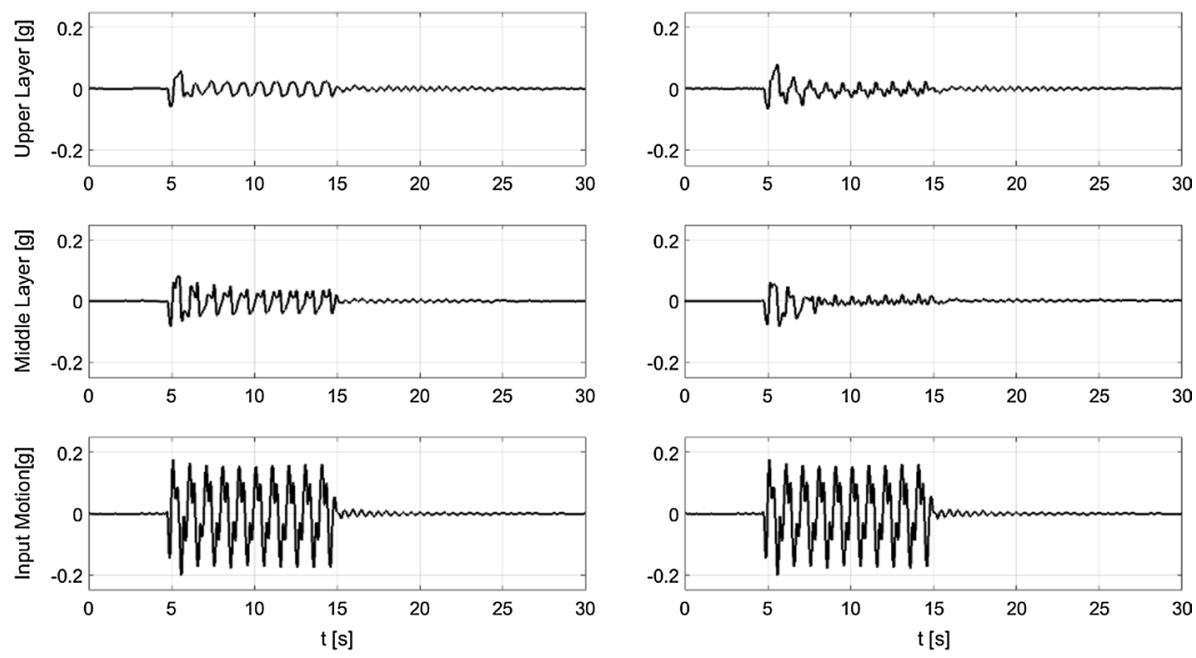

(a) Improved Region

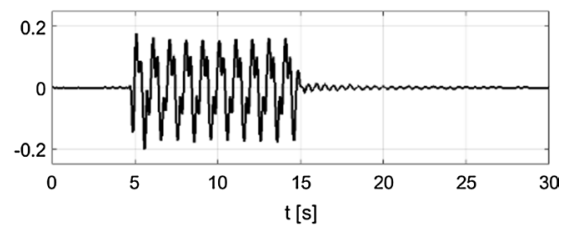

(b) Unimproved Region

Fig. 8 Acceleration time-histories for soil with vertical drains EQ2
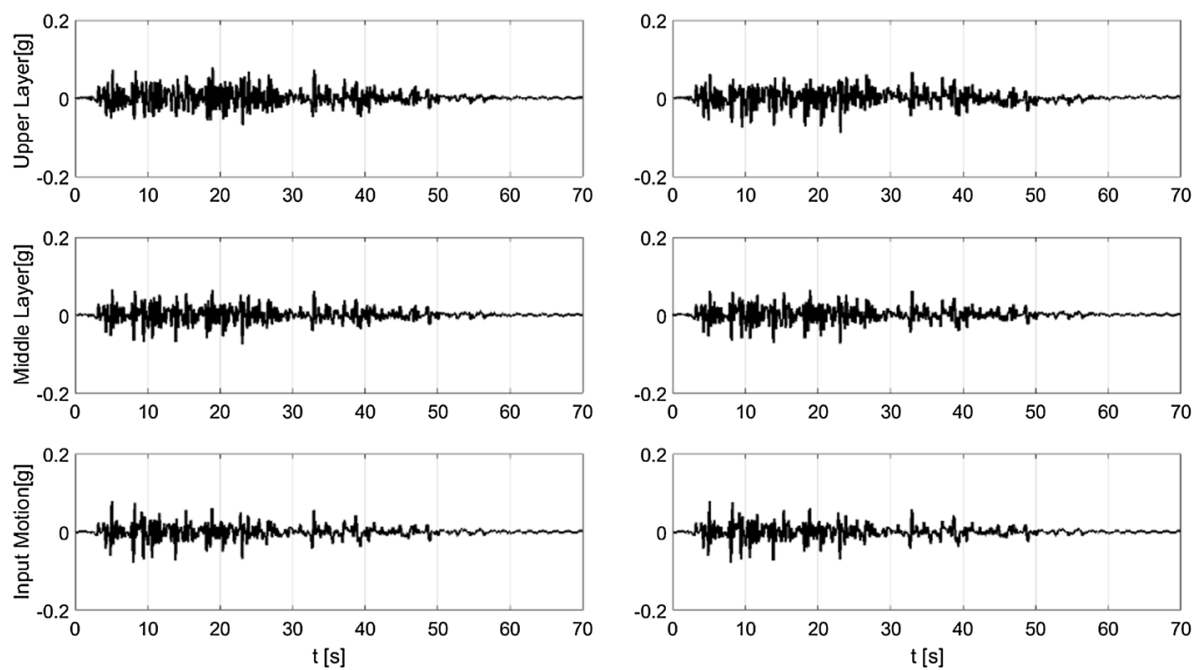

(a) Improved Region

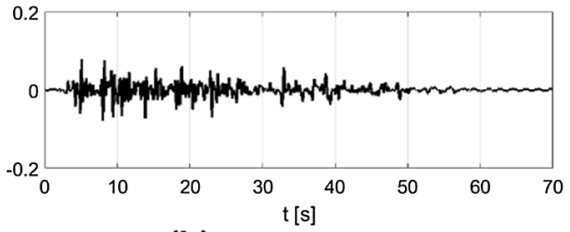

(b) Unimproved Region

Fig. 9 Acceleration time-histories for soil with vertical drains Imperial Valley

\section{Dynamic response}

\subsection{Acceleration time-histories of soil}

Acceleration time histories for the middle and upper layers of the mitigated and the unmitigated soil together with the input motions are presented in this section, for the second (Fig. 8) and the Imperial valley earthquakes (Fig. 9). 
Acceleration time histories for the second earthquake in the region with drains (Fig. 8a) show deamplification of the input motion especially at the upper layer, after the first cycle of shaking. In the unimproved region (Fig. 8b), complete acceleration decoupling for both heights were presented as a consequence of high levels of pore pressure that caused softening in the soil suggesting complete liquefaction in the stratum. A slight difference in the acceleration reduction between both regions was observed at both heights of the soil. In the region with drains, less decoupling was generated as the vertical drains improved drainage by controlling the excess pore pressure generation especially in the nucleus drains zone. Nevertheless, the drains were not able to avoid complete liquefaction as this earthquake was a strong event and due to the low shear reinforcement given by the drains. Similar results in soil acceleration decoupling were presented between Brennan's work and this study due to the high levels of excess pore pressures that induced softening in the soil as a consequence of strong input motions in both cases.

For the Imperial Valley earthquake (Fig. 9), acceleration in the soil stratum for the middle and upper layers presented a slightly amplification suggesting dilation in the soil. Increase of the soil density was expected as a result of consecutives shaking. This soil behaviour allowed a lower generation of excess pore pressure in small earthquakes and in presence of high bearing pressures (Dashti et al. 2010b).

\subsection{Foundation acceleration}

Figure 10 shows the foundations horizontal acceleration response for the second earthquake. In the soil with drains (Fig. 10a), the acceleration deamplificated in $0.1 \mathrm{~g}$ as a result of the complete soil softening previously observed from soil accelerations. The soil with no drains (Fig. 10b) presented a larger deamplification of the input motion showing an average value of $0.03 \mathrm{~g}$ during all the shaking.

Acceleration reduction on the foundations as a result of soil softening was expected for this earthquake. In the mitigated region, drains provided a rapid control of pore pressures generation especially in the soil surrounded by the nucleus drains, resulting in higher acceleration magnitudes compared to the values obtained for the unmitigated zone. Although

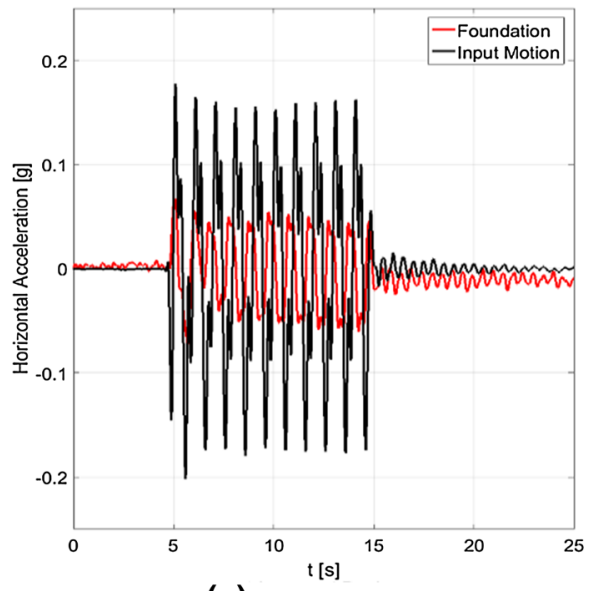

(a) Improved Region

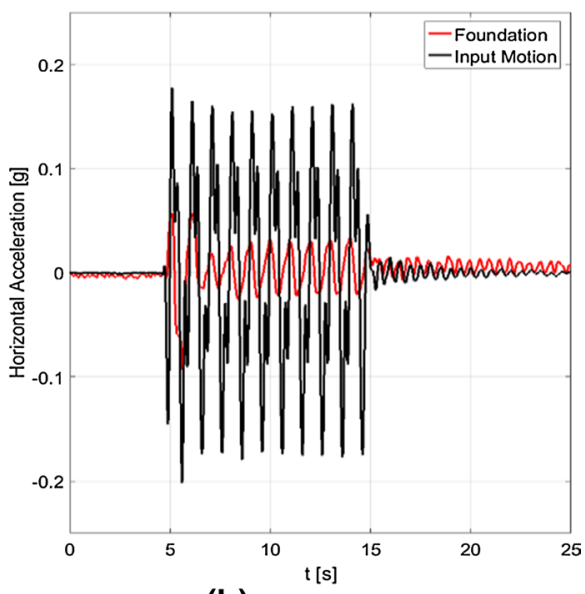

(b) Unimproved Region

Fig. 10 Horizontal acceleration of foundations (EQ2) 
an amplification of the foundation acceleration was expected in the case of the mitigated stratum, the soil decreased the transfer of the input motion to the foundation as a consequence of complete liquefaction reducing the probability of structure rocking. In Fig. 11, the response spectra has been plotted for this earthquake. As on the acceleration time histories, it is clear from this figure that the foundation response is much smaller than the input motion owing to soil liquefaction. Further, it is possible to observe that the foundation response is marginally higher in the presence of drains.

Horizontal acceleration of the foundations for the region with drains (Fig. 12a) and no drains (Fig. 12b) together with the Imperial Valley input motion are shown in Fig. 12. An amplification of the acceleration input motion was observed and spikes of more than $0.1 \mathrm{~g}$ in the case of soil with drains were observed as a consequence of dilation presented on the soil. The raise in soil density caused soil to re-stiffen and lower generation of pore pressures in the soil also helped this process.

In both regions, similar behaviour of foundations acceleration response were observed; however, in the case of soil with drains moderately higher values were obtained due to the effective action of drains in maintaining small levels of excess pore pressures. Moreover, the acceleration spikes in the mitigated zone presented in Fig. 12a, were generated due to the shear reinforcement provided by the vertical drains as complete soil softening was not reached for the Imperial Valley earthquake. In addition, as a consequence of the foundation acceleration amplification the probability of the structure to suffer settlement and possible rotation reduced in both cases; nevertheless, the risk of deviatoric deformations in the soil due to ratcheting increased.

\section{Conclusions}

Understanding vertical drains performance below buildings along with the foundation dynamic response is crucial in the estimation of the efficiency of this soil improvement technique. The selected drain arrangement show an effective behaviour in terms of the

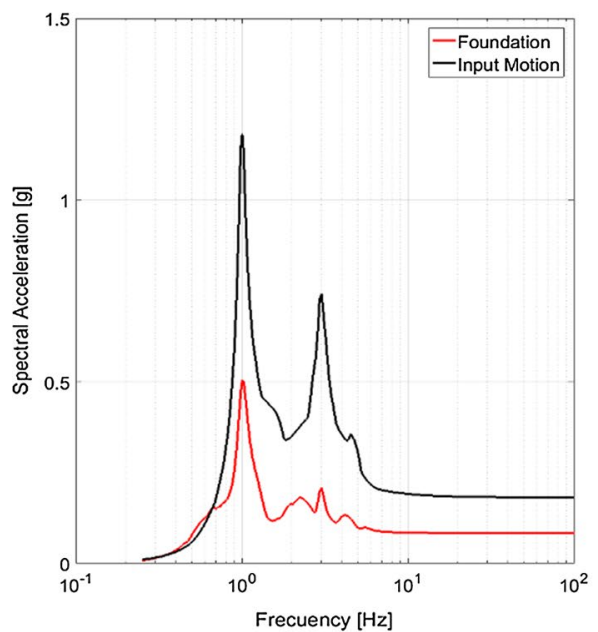

(a) Improved Region

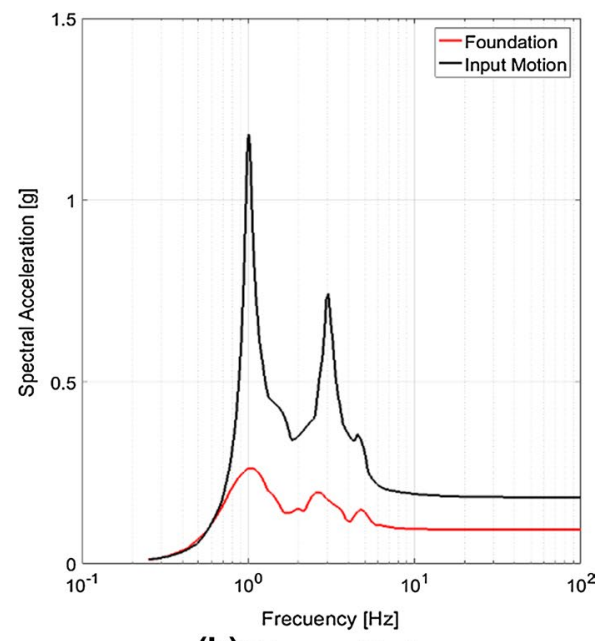

(b) Unimproved Region

Fig. 11 Response Spectra (EQ2) 

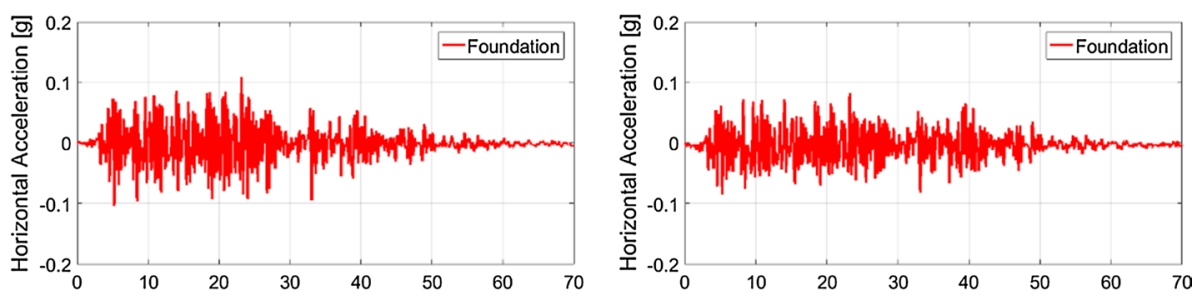

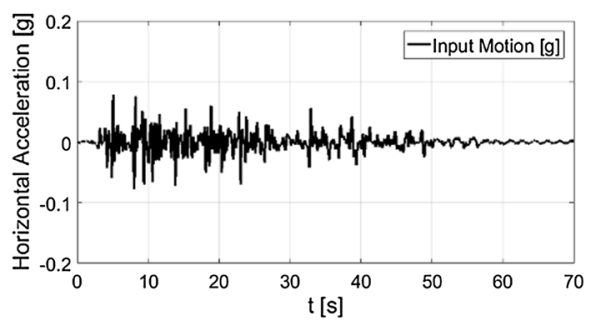

(a) Improved Region

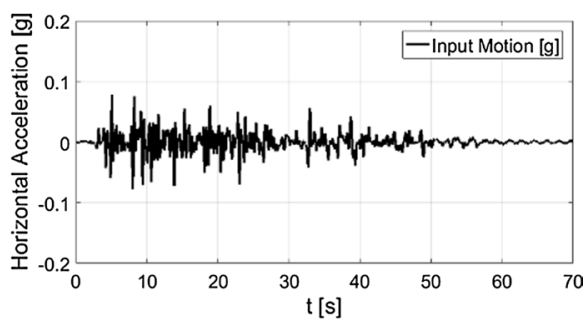

(b) Unimproved Region

Fig. 12 Horizontal acceleration of foundations (Imperial Valley)

dissipation of soil excess pore pressures, decreasing the duration for which high excess pore pressures values are held and allowing vertical and horizontal inflow fluid. Moreover, the use of rubble brick as coarse high permeable material contributes to the adaption of this technique in the field in a sustainable fashion both in terms of low costs and reuse of waste material.

The analysis of results verified the effectiveness of the drains in the improved soil compared to the unimproved region, as all the drain rings managed to control the high values of excess pore pressure depending on their location in the stratum. In addition, a significant contribution was made by the nucleus drains below the foundation, providing a fluid pattern of rapid dissipation and highlighting the presence of drains placed directly below the shallow foundation of the structure. The reduction of elevated excess pore pressures in presence of drains generated positive results in terms of settlement, as minor volumetric strains due to settlement and consolidation in the soil were presented. However, deviatoric strains were generated by the foundation confirming the importance of evaluating this remediation technique in real contexts. Increasing the number of vertical drains below the structure may not guarantee complete settlement reduction or sufficient soil reinforcement to avoid complete liquefaction.

Vertical drains efficacy is often linked to the reduction of structural settlement. This is achieved by lowering the magnitude and time for which the higher pore pressures persist. In this paper, the drain group studied performed well from this point of view. Nevertheless, the presence of drains also acts as a shear reinforcement of the liquefying soil, which in turn should lead to a reduction in structural settlements. This aspect worked less properly in this study as the drains were constructed prior to apply high gravity in the centrifuge.

Acknowledgements First author is supported by funding of the Peruvian Council of Science, Technology and Technological Innovation-CONCYTEC. 
Open Access This article is distributed under the terms of the Creative Commons Attribution 4.0 International License (http://creativecommons.org/licenses/by/4.0/), which permits unrestricted use, distribution, and reproduction in any medium, provided you give appropriate credit to the original author(s) and the source, provide a link to the Creative Commons license, and indicate if changes were made.

\section{References}

Adalier K, Elgamal AW, Martin GR (1998) Foundation liquefaction countermeasures for earth embankments. J Geotech Geoenviron Eng 124(6):500-517

Adamidis O, Madabhushi SPG (2015) Deformation mechanisms under shallow foundations during earthquake-induced liquefaction. In: Proceedings of 6th international conference on earthquake geotechnical engineering

Badanagki M, Dashti S, Kirkwood P (2018) Influence of dense granular columns on the performance of level and gently sloping liquefiable sites. J Geotech Geoenviron Eng 144(9):04018065

Bertalot D, Brennan AJ (2015) Influence of initial stress distribution on liquefaction-induced settlement of shallow foundations. Géotechnique 65(5):418-428

Brennan AJ (2004) Vertical drains as a countermeasure to earthquake-induced soil liquefaction. PhD dissertation, University of Cambridge

Brennan AJ, Madabhushi SPG (2002) Effectiveness of vertical drains in mitigation of liquefaction. Soil Dyn Earthq Eng 22(9-12):1059-1065

Brennan AJ, Madabhushi SPG, Houghton NE (2006) Comparing laminar and equivalent shear beam (ESB) containers for dynamic centrifuge modelling. In: Physical modelling in geotechnics, proceedings of the 6th international conference ICPMG, vol 6, pp 171-176

Coelho PALF, Haigh SK, Madabhushi SPG, O'Brien T (2004) Centrifuge modeling of the use of densification as a liquefaction resistance measure for bridge foundations. In: 13th world conference on earthquake engineering, $\mathrm{p} 15$

Cubrinovski M, Bradley B, Wotherspoon L et al (2011) Geotechnical aspects of the 22 February 2011 Christchurch earthquake. Bull NZ Soc Earthq Eng 44(4):205-226

Dashti S, Bray JD, Pestana JM, Riemer M, Wilson D (2010a) Centrifuge testing to evaluate and mitigate liquefaction-induced building settlement mechanisms. J Geotech Geoenviron Eng 136(7):918-929

Dashti S, Bray JD, Pestana JM, Riemer M, Wilson D (2010b) Mechanisms of seismically induced settlement of buildings with shallow foundations on liquefiable soil. J Geotech Geoenviron Eng 136(1):151-164

Etxeberria M, Vázquez E, Marí A, Barra M (2007) Influence of amount of recycled coarse aggregates and production process on properties of recycled aggregate concrete. Cem Concr Res 37(5):735-742

Florin VA, Ivanov PL (1961) Liquefaction of saturated sandy soils. In: The 5th international conference on soil mechanics and foundation engineering, Paris, pp 101-111

García-Torres S, Madabhushi SPG (2018) Earthquake-induced liquefaction mitigation under existing buildings using drains. In: Proceedings of the 9th international conference on physical modelling in geotechnics (ICPMG 2018), London, UK, pp 1181-1186

Ghajj K, Dilrukshi A, Subasinghe N (2008) Study on advantages of using coir dust in vertical drains for the improvement of soft clay. In: Women's career advancement and training \& development in the construction industry, pp 1343-1357

Haigh SK, Madabhushi SPG, Soga K, Taji Y, Shamoto Y (2000). Lateral spreading during centrifuge model earthquakes. In: ISRM international symposium. international society for rock mechanics and rock engineering

Haigh SK, Eadington J, Madabhushi SPG (2012) Permeability and stiffness of sands at very low effective stresses. Géotechnique 62(1):69

Heron C, Haigh S, Madabhushi SPG (2014) Susceptibility of shallow foundation to rocking and sliding movements during seismic loading. In: Ilki A, Fardis MN (eds) Seismic evaluation and rehabilitation of structures, geotechnical, geological and earthquake engineering, vol 26. Springer, Cham, pp 407-424

Howell R, Rathje EM, Kamai R, Boulanger R (2012) Centrifuge modeling of prefabricated vertical drains for liquefaction remediation. J Geotech Geoenviron Eng 138(3):262-271

Iai S, Koizumi K, Noda S, Tsuchida H (1988) 2. Large scale model tests and analyses of gravel drains. Un’yushō Kōwan Gijutsu Kenkyūjo 
Ledesma EF, Jiménez JR, Ayuso J, Fernández JM, de Brito J (2015) Maximum feasible use of recycled sand from construction and demolition waste for eco-mortar production-part-I: ceramic masonry waste. J Clean Prod 87:692-706

Liu L, Dobry R (1997) Seismic response of shallow foundation on liquefiable sand. J Geotech Geoenviron Eng 123(6):557-567

Madabhushi G (2014) Centrifuge modelling for civil engineers. CRC Press, Boca Raton

Madabhushi SPG, Houghton NE, Haigh SK (2006). A new automatic sand pourer for model preparation at University of Cambridge. In: Proceedings of the 6th International conference on physical modelling in geotechnics. Taylor \& Francis Group, London, UK, pp 217-222

Miranda LF, Constantino CS, Monich CR, de M. Neto AA (2012) Use of recycled sand produced at construction sites in bedding mortars. J Mater Civ Eng 25(2):236-242

Mitrani H, Madabhushi SPG (2012) Rigid containment walls for liquefaction remediation. J Earthq Tsunami 6(04):1250017

Nataatmadja A, Tan YL (2001) Resilient response of recycled concrete road aggregates. J Transp Eng 127(5):450-453

Olarte J, Paramasivam B, Dashti S, Liel A, Zannin J (2017) Centrifuge modeling of mitigation-soil-foundation-structure interaction on liquefiable ground. Soil Dyn Earthq Eng 97:304-323

Orense RP, Morimoto I, Yamamoto YA, Yumiyama T, Yamamoto H, Sugawara K (2003) Study on walltype gravel drains as liquefaction countermeasure for underground structures. Soil Dyn Earthq Eng 23(1):19-39

Paramasivam B, Dashti S, Liel AB, Olarte JC, Junior LS, Gomes LS (2017) Performance of inelastic, shallow founded structures on liquefiable ground and the effectiveness of mitigation strategies. In: The 16th world conference on earthquake engineering. Santiago

Paramasivam B, Dashti S, Liel A (2018) Influence of prefabricated vertical drains on the seismic performance of structures founded on liquefiable soils. J Geotech Geoenviron Eng 144(10):04018070

Rao A, Jha KN, Misra S (2007) Use of aggregates from recycled construction and demolition waste in concrete. Resour Conserv Recycl 50(1):71-81

Ravindrarajah RS, Loo YH, Tam CT (1987) Recycled concrete as fine and coarse aggregates in concrete. Mag Concrete Res 39(141):214-220

Sasaki Y, Taniguchi E (1982) Large scale shaking table tests on the effectiveness of gravel drains for liquefiable sand deposits. In: Proceedings of conference soil dynamics and earthquake engineering, Southampton 2843, vol 857

Schofield A (1980) Cambridge geotechnical centrifuge operations. Géotechnique 30(3):227-268

Seed HB, Booker JR (1977) Stabilization of potentially liquefiable sand deposits using gravel drains. J Geotech Geoenviron Eng 103(ASCE 13050)

Stringer ME, Madabhushi SPG (2009) Novel computer-controlled saturation of dynamic centrifuge models using high viscosity fluids. Geotech Test J 32(6):559-564

Tanaka H, Kita H, Iida T, Saimura Y (1996) Countermeasure for liquefaction using steel sheet pile with drain capability. In: Proceedings of international conference on engineering for protection from natural disasters, pp 643-655

Ulsen C, Kahn H, Hawlitschek G, Masini EA, Angulo SC, John VM (2013) Production of recycled sand from construction and demolition waste. Constr Build Mater 40:1168-1173

Vinodhini A, Dhanalakshmi G (2016) Effect of brick chips aggregate and curing condition on the strength of concrete. Int J Adv Res Basic Eng Sci Technol (IJARBEST) 2(3):97-100

Watanabe T (1966) Damage to oil refinery plants and a building on compacted ground by the Niigata earthquake and their restoration. Soils Found 6(2):86-99

Yasuda S (2007) Remediation methods against liquefaction which can be applied to existing structures. In: Earthquake geotechnical engineering. Springer, Dordrecht, pp 385-406

Yoshida N, Tokimatsu K, Yasuda S, Kokusho T, Okimura T (2001) Geotechnical aspects of damage in Adapazari city during 1999 Kocaeli, Turkey earthquake. Soils Found 41(4):25-45

Publisher's Note Springer Nature remains neutral with regard to jurisdictional claims in published maps and institutional affiliations. 